\title{
What an Optimist Looks Like: Separating Optimistic Bias from Social Reality
}

\author{
Amber A. Fultz, Frank J. Bernieri \\ School of Psychological Science, Oregon State University, Corvallis, OR, USA \\ Email: Frank.Bernieri@oregonstate.edu
}

How to cite this paper: Fultz, A. A., \& Bernieri, F. J. (2018). What an Optimist Looks Like: Separating Optimistic Bias from Social Reality. Psychology, 9, 413-426. https://doi.org/10.4236/psych.2018.93026

Received: January 18, 2018

Accepted: March 27, 2018

Published: March 30, 2018

Copyright $\odot 2018$ by authors and Scientific Research Publishing Inc. This work is licensed under the Creative Commons Attribution International License (CC BY 4.0).

http://creativecommons.org/licenses/by/4.0/

\section{(c) (i) Open Access}

\begin{abstract}
Optimists hold positive expectancies for their future, which some have suggested leads to advantages in the social realm (Carver, Scheier, \& Segerstrom, 2010). Unfortunately, the research supporting this notion is scant and suffers from the confound that self-reports from optimists reflect their optimistic perspective. To address this issue, the present study examined the impact of optimism on interpersonal outcomes assessed from the perspective of those in relationships with each target. We recruited 182 participants to complete a series of psychological measures and interpersonal activities over the course of ten weeks. Participants rated themselves and each other on the five-factor traits at three stages in the developing relationship: zero-acquaintance, after their first conversation with each other, and after nine weeks of acquaintance. Two additional informants nominated by each target as those who knew them well (i.e. friends or family members) provided more extensive personality descriptions using a California Q-Set. Optimists consistently rated themselves as more agreeable and less neurotic than those low in optimism, but only the difference in neuroticism was detectable by perceivers. Furthermore, this difference was discernable only after nine-weeks of acquaintanceship had been established. Target optimism had no impact on first impressions. Although there may exist an optimistic personality profile across the five major traits, we found little evidence to suggest that anything other than lower neuroticism contributes to the impact that optimism might have on one's social life and relationships.
\end{abstract}

\section{Keywords}

Optimism, Interpersonal Processes, Five-Factor Traits

\section{Introduction}

Optimism plays an important role in many aspects of our lives (Wrosch \& 
Scheier, 2003). Although much of the attention has been paid to its impact on physical health and subjective well-being (Mann, 2001; Sears et al., 2004; Smith, Young, \& Lee, 2004), there is some evidence to indicate that the benefits of optimism also extend to interpersonal experiences and relationships (Carver, Scheier, \& Segerstrom, 2010; Carver \& Scheier, 2014). For example, optimists report experiencing more satisfaction in marital relationships (Smith, Ruiz, Cundiff, Baron, \& Nealey-Moore, 2013), more support in their social relationships (Abend \& Williamson, 2002; Brissette, Scheier, \& Carver, 2002; Wimberly, Carver, \& Antoni, 2008), and are less likely to have an anxious attachment style (Heinonen, Räikkönen, Keltikangas-Järvinen, \& Strandberg, 2004). But are these interpersonal outcomes real or are they a result of an optimistic bias in perception and construal? The very nature of the optimist is to view and report their experiences (e.g., relationships) in a favorable light. Therefore, the question remains as to whether optimists have been reporting their true social realities to researchers or simply putting a positive spin on them. Given the few studies on the topic, the answer to this question remains speculative at best (Carver et al., 2010; Carver \& Scheier, 2014). This report attempted to address this issue by measuring the social realities of optimists from the perspective of those who live, work, and play with them.

The problem with assessing interpersonal outcomes from self-reports is one of validity. Self-reports reflect subjective impressions of outcomes (e.g., "my marriage is wonderful and we never fight") rather than actual outcomes (e.g., their spouse agrees with them). Although the overarching conclusion from previous investigations has been that optimists may enjoy an "interpersonal advantage" (Carver et al., 2010; Carver \& Scheier, 2014), the question remains as to whether this is an actual advantage or whether it is an optimistic bias (Brown, 1986; Krueger, 1998). In order to provide a more objective assessment of interpersonal outcomes, we need to measure not just one relationship, but a sample of relationships from optimists to get a more stable estimate of their social lives.

"Interpersonal outcomes" can mean many things. A good outcome could be defined as being considered warm and likable by others (Smith et al., 2013). Alternatively, a good outcome could be defined as feeling emotionally supported (Wimberly et al., 2008). Or perhaps a good outcome is one where one individual has some influence over another (Cialdini, 2008). All of these are reasonable and important to consider, however in the present study we have focused on others' perceptions of a target. For the purposes of this study, a good interpersonal outcome is considered one where an observer forms a positive impression of a target.

We operationalized a positive impression in terms of the five-factor model of personality traits (Allik, 2016; Digman, 1990; Wiggins, 1996). Chaplin and colleagues studied first impressions and described a positive personality trait profile as one where a target is viewed by others to be low in neuroticism, high in agreeableness, and high in the remaining three traits (Chaplin, Phillips, Brown, Clanton, \& Stein, 2000). Interestingly, the personality correlates of optimism re- 
veal a similar pattern. Optimism has been found to correlate negatively with neuroticism and positively with agreeableness, extraversion, and conscientiousness (Lounsbury, Saudargas, \& Gibson, 2004; Milligan, 2003; Sharpe, Martin, \& Roth, 2011). Therefore, from the perspective of trait theory, optimists have a personality profile that should result in others forming positive impressions of them.

But having a positive personality trait profile doesn't necessarily mean that others will immediately perceive it. The accuracy with which people perceive others is limited at zero acquaintance (Kenny \& West, 2008), although it can improve substantially as people become more acquainted over the course of a relationship (Biesanz, West, \& Millevoi, 2007; Brown \& Bernieri, 2017). We know, for example, that both optimists and their romantic partners report greater relationship satisfaction (Srivastava, McGonigal, Richards, Butler, \& Gross, 2006). Therefore, the positive, optimistic trait profile is likely well-known by those in established relationships with optimists, such as intimate partners. This leads to the question of when, or at what point in a developing relationship do people begin to see the optimist's positive personality profile? Brown \& Bernieri (2017), for example, found that a person's agreeableness as measured by the NEO PI-R (Costa \& McCrae, 1992) was not accurately perceived by others at first encounter but became apparent after nine weeks of acquaintanceship. It may be that optimists are immediately perceived as optimists, or perhaps it takes several weeks before one comes to know them as such.

\section{The Present Investigation}

The primary objective of this report was to extend our knowledge of optimism to the understudied realm of interpersonal processes. We employed the Life Orientation Test-Revised (LOT-R; Scheier, Carver, \& Bridges, 1994), which measures the tendency to expect positive future events (Scheier \& Carver, 1985). The methodological advancement of this study is that it measured interpersonal outcomes by sampling eight different relationships for each participant. This contrasts sharply with studies that have merely collected subjective impressions of one's own social life, which of course is confounded with the optimism construct itself. Instead, we asked the friends and family members of participants to evaluate their personalities. Although we know optimists have more positive personalities, we do not know whether this fact is apparent to people who are closely acquainted with them.

In addition to measuring established relationships, this study tracked the impressions of optimists through the development of relationships from zero acquaintance. This way, we were able to assess whether the optimistic personality was visible to strangers from the very beginning of a relationship. Groups of 5 7 university students, all unacquainted with one another (which was determined prior to group assignment), met repeatedly over a period of ten weeks for a total of 50 hours. Over this time period, in addition to completing a large number of 
psychological assessments, they participated in a number of interpersonal and relationship-building activities outside of the lab environment designed to better acquaint themselves with one another (Brown \& Bernieri, 2017). Among these activities were: 1) eating meals, 2) traveling, 3) cleaning a house, 4) socializing, and 5) competing against each other.

\section{Method}

\subsection{Participants}

The data for this report came from a larger study designed to investigate the impact of personality traits and interpersonal skills on relationship formation (e.g., Brown \& Bernieri, 2017). Participants were 182 undergraduates who received academic credit for enrolling in a "Psychological Assessment" research practicum that was open to all academic majors. Three groups (usually 21 participants) were run within a given academic term. We collected data in nine terms over a period of 5 years. Participants were treated in accordance with the "Ethical Principles of Psychologists and Code of Conduct" (American Psychological Association, 2002). Informed consent was obtained from all individual participants included in the study.

Of the 182 participants, 69 were males and 113 were females. Participant ages ranged from 18 to 54 years $(M=22.1, S D=4.79)$ and $93 \%$ of them identified English as their first language. A total of 144 participants were Caucasian (79\%), 3 were African American (2\%), 11 were Hispanic (6\%), 8 were Asian/Pacific Islander (4\%), 6 were American Indian/Alaskan Native (3\%), and 10 selected other (6\%). There were 22 freshman (12\%), 25 sophomores (14\%), 53 juniors (29\%), 73 seniors (40\%) and 9 that selected other (5\%).

\subsection{Measures}

Target personality. According to Carver \& Scheier (2014), optimism can be understood as one's tendency to hold positive expectancies for the future. Their scale, the Life Orientation Test-Revised (LOT-R; Scheier et al., 1994), is a relatively brief six-item measure that assesses this. Responses are made on a 5-point scale where half of the items are reversed scored. Scale responses range from strongly disagree to strongly agree. The reported internal consistency in terms of Cronbach's alpha is .78.

To assess the five-factor traits we had participants complete the NEO PI-R Form S (Costa \& McCrae, 1992). The NEO PI-R contains 240 items and takes approximately 35 - 45 minutes to complete. Participants responded to each item on a 5-point rating scale that ranged from strongly disagree to strongly agree. Costa \& McCrae (1992) reported coefficient alphas of .92, .89, .87, .86, and .90 for the neuroticism, extraversion, openness, agreeableness, and conscientiousness domains, respectively.

Participants also provided self-ratings for each five-factor trait using the Ten Item Personality Inventory (TIPI; Gosling, Rentfrow, \& Swann, 2003), which is a 
short form proxy for the NEO-PI-R. This measure was chosen because it was brief enough to employ in a round-robin personality perception study (e.g., Kenny, 1994), which we employed. The TIPI was always completed during the same experimental session where participants rated the personality traits of their group members. The first personality rating session took place on the first day of the study and is referred to as the zero acquaintance session (Figure 1). A second personality rating session called the five-minute session (Figure 2) occurred two days later when participants got a chance to have their first five minute conversation with each individual member of their group. The final personality rating session took place nine weeks later when everyone was well-acquainted with one another. Thus, participants completed the TIPI on themselves three different times over the course of the study.

Perceiver ratings. We had two different sets of informants provide personality descriptions of our participants. The participants' group members constituted one set of informants. Since most groups had 7 total participants, there usually were six informants in this set. Group members completed their personality ratings using the TIPI as well. This allowed us to compute a group consensus

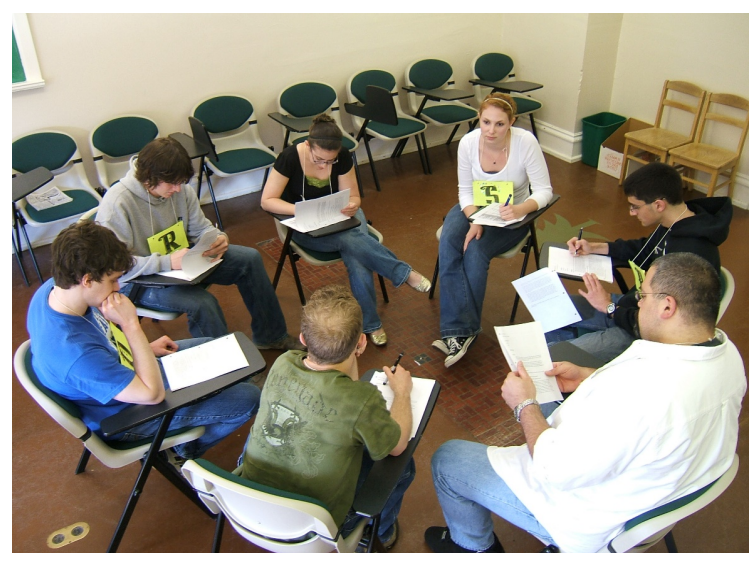

Figure 1. Participants engaging in the zero-acquaintance ratings.

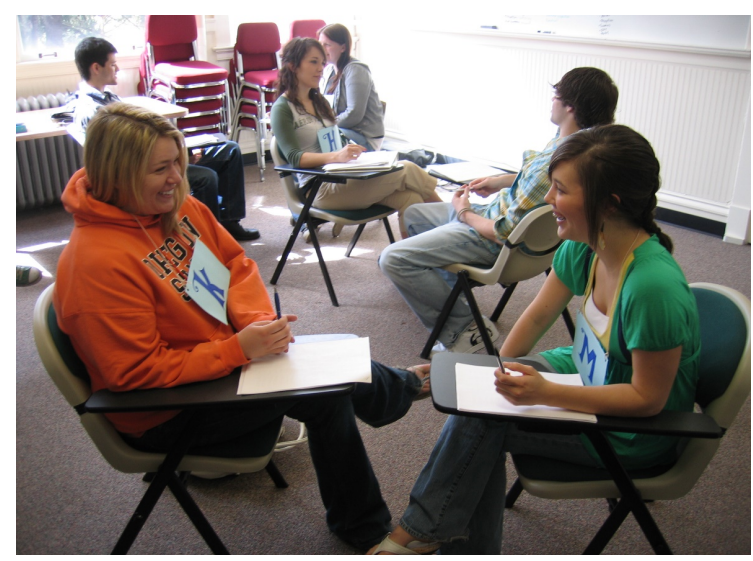

Figure 2. Participants engaging in the five-minute interaction. 
judgment for each of the five-factor traits (Hall, Bernieri, \& Carney, 2005).

For the other set of informants, participants recruited two people (e.g., family, roommates, or friends) who knew them well. Instead of using the TIPI, they provided a Q-sort description of the target employing the California Q-Set (Block, 1961). This Q-set consists of 100 cards each with a descriptive statement (e.g., "Behaves in an ethically consistent manner; is consistent with own personal standards", or "Tends to be self-defensive"). An evaluator's task is to arrange the 100 cards into a normal distribution, with the tails indicating cards that are least descriptive of a target's personality and cards that are most descriptive of a target's personality. A set of Q-sort cards and instructions were sent to all informants who could not come to the lab in person to complete this task. Descriptions from the two informants were combined, yielding an average placement for each card.

\section{Results}

Personality correlates of optimism. We first replicated and confirmed the previously reported associations between optimism and personality using the NEO-PI-R. We expected to find that optimists would be less neurotic, and more agreeable, extraverted, and conscientious (Lounsbury et al., 2004; Milligan, 2003; Sharpe et al., 2011). Our findings are displayed in Table 1 and replicated nearly every effect. The LOT-R correlated negatively with neuroticism $(r=-.47, p<.001)$ and correlated positively with agreeableness $(r=.18, p<.05)$, extraversion $(r=.23, p$ $<.01)$, and openness $(r=.15, p<.05)$. However, optimism did not correlate significantly with conscientiousness $(r=.04, p=$ n.s.).

We employed the briefer TIPI (Gosling et al., 2003) to assess interpersonal outcomes, which we operationalized as impressions of personality. Participants rated themselves as well as every other member of their group using the TIPI. Self-ratings of the TIPI were collected at three time points: 1) at the very beginning of the study, 2) on day 2 of the study when participants were talking with each member of their group for the very first time, and 3) nine weeks in to the study. The test-retest correlations across the 3 time periods ranged from $r=.47$ to $r=.81$. The TIPI self-ratings were averaged over the three time periods.

Table 1. Correlations between optimism and self-report measures of the five-factor traits.

\begin{tabular}{|c|c|c|}
\hline Factor & $\begin{array}{c}\text { NEO-PI-R }^{\mathrm{a}} \\
N=182\end{array}$ & $\begin{array}{c}\text { TIPI }^{\mathrm{b}} \text { Composite } \\
\quad N=176\end{array}$ \\
\hline Neuroticism & $-.47^{\star * *}$ & $-.39^{* * *}$ \\
\hline Agreeableness & $.18^{*}$ & $.27^{\star * *}$ \\
\hline Extraversion & $.23^{* *}$ & .00 \\
\hline Openness & $.15^{\star}$ & .13 \\
\hline Conscientiousness & .04 & .14 \\
\hline
\end{tabular}

Note. Due to missing or corrupt data, 176 participants were used in the TIPI analyses. ${ }^{a} \mathrm{~A} 240$ item measure of the five-factor traits (Costa \& McCrae, 1992). ${ }^{b}$ The Ten-Item Personality Inventory (Gosling et al., 2003). ${ }^{\star} p<.05 .{ }^{* *} p<.01 .{ }^{* *} p<.001$. 
The correlations between the mean TIPI self-ratings and NEO-PI-R scores for neuroticism, extraversion, openness, agreeableness, and conscientiousness were $.67, .65, .56, .65$, and .64 , respectively. All were significant at the $p<.001$ level.

The next step was to determine whether the personality correlates of optimism found using the NEO PI-R would replicate when using the much briefer TIPI. The correlations between the TIPI self-ratings and optimism appear in the right column of Table 1 . Optimism correlated negatively with neuroticism ( $r=$ $-.39, p<.001)$ and positively with agreeableness $(r=.27, p<.001)$, but did not correlate significantly with any other trait.

The slight discrepancy in personality correlates of optimism across the two different trait measures could be due to the lower content validity of the TIPI, which contained only two items to assess a given trait. Another possibility is that the social context of the rating procedure introduced a self-presentation motive to those completing the self-descriptions. To the extent being immersed in a group temporarily influenced their working self-concept (Markus \& Wurf, 1987), we would expect the self-ratings of group members to reflect their working self-concept as a member of that group, which may differ from the self-construct activated when taking the NEO PI-R at home. Another self-presentation motive that could have impacted TIPI ratings involves the possible evaluation apprehension that would come from knowing that the other group members were evaluating them on the very same scale. For some participants, this may have stimulated a self-verification motive (Swann, 1990) or an increase in their objective self-awareness (Wicklund, 1975) that would bring their self-descriptions closer in alignment to those they anticipated would be generated by their group. In other words, knowing that their self-descriptions would be compared to the consensus ratings may have inhibited the self-enhancement bias that normally impacts self-assessments (Greenwald, 1980; John \& Robins, 1994). All of these issues highlight the limitations of extrapolating self-report data to the interpersonal domain.

Experimentally manipulated acquaintances. The next question we addressed was whether the self-reported personality correlates of optimism (i.e., neuroticism and agreeableness) were detected and confirmed by others. More interesting, perhaps, is the question of when they became noticeable to others. To assess this, we conducted a series of $t$-tests on the TIPI personality descriptions (on both self-ratings and consensus ratings) across the three stages of participants' relationships.

In order to test whether optimists had different self-reported personalities as measured with the TIPI, we performed a median split on the LOT-R scores to form high and low optimism samples. Table 2 displays the mean ratings of Neuroticism and Agreeableness by optimism level, time of assessment, and whether the rating was a self-rating or the group consensus rating on the target. Participants high in optimism rated themselves as being less neurotic at 
Table 2. Mean Trait ratings of target traits across three time periods by source (self vs others).

\begin{tabular}{|c|c|c|c|c|c|c|c|}
\hline \multirow{2}{*}{$\begin{array}{l}\text { TIPI }^{\mathrm{a}} \text { Trait } \\
N=176\end{array}$} & \multirow{2}{*}{ Optimism $^{\mathrm{b}}$} & \multicolumn{2}{|c|}{$\begin{array}{c}\text { Zero } \\
\text { Acquaintance }\end{array}$} & \multicolumn{2}{|c|}{ First Conversation } & \multicolumn{2}{|c|}{ After Nine Weeks } \\
\hline & & Self & $\begin{array}{c}\text { Group } \\
\text { Consensus }\end{array}$ & Self & $\begin{array}{c}\text { Group } \\
\text { Consensus }\end{array}$ & Self & $\begin{array}{c}\text { Group } \\
\text { Consensus }\end{array}$ \\
\hline \multirow{4}{*}{ Neuroticism } & $\operatorname{High}(N=82)$ & 5.2 & 6.7 & 5.2 & 5.9 & 5.3 & 5.7 \\
\hline & Low $(N=94)$ & 6.7 & 6.8 & 6.4 & 6.1 & 6.5 & 6.3 \\
\hline & Difference (high-low) & -1.5 & -.1 & -1.2 & -.2 & -1.2 & -.6 \\
\hline & $t_{(174)}$ & $-4.33^{* * *}$ & -.62 & $-3.77^{\star * * c}$ & -1.40 & $-3.12^{\star * c}$ & $-2.59^{*}$ \\
\hline \multirow{4}{*}{ Agreeableness } & $\operatorname{High}(N=82)$ & 10.5 & 8.9 & 10.7 & 10.2 & 10.4 & 9.9 \\
\hline & Low $(N=94)$ & 9.6 & 9.1 & 10.0 & 10.0 & 9.5 & 9.6 \\
\hline & Difference (high-low) & +.9 & -.2 & +.7 & +.2 & +.9 & +.3 \\
\hline & $t_{(174)}$ & $+2.74^{\star \star}$ & -1.23 & $+2.31^{\star c}$ & +1.05 & $+2.54^{\star}$ & +1.05 \\
\hline
\end{tabular}

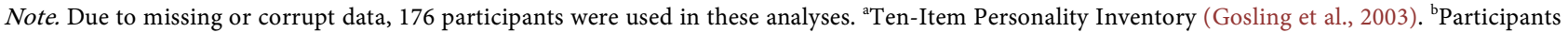
were split into high-low optimism groups on the basis of their LOT-R scores. ${ }^{c} t_{(173)} \cdot{ }^{*} p<.05 .{ }^{* *} p<.01 .{ }^{* * *} p<.001$.

zero-acquaintance $\left(t_{(174)}=-4.33, p<.001, d=.66\right)$, after the five-minute interaction $\left(t_{(173)}=-3.77, p<.001, d=.57\right)$, and after nine-weeks of acquaintance $\left(t_{(173)}=\right.$ $-3.12, p<.01, d=.47)$. However group members' first impressions of them were unaffected by their optimism at zero-acquaintance $\left(t_{(174)}=-.62, p=\mathrm{n} . \mathrm{s}\right.$.) or after the five minute interaction $\left(t_{(174)}=-1.40, p=\right.$ n.s.). By nine weeks however, group members rated optimistic targets significantly lower in neuroticism $\left(t_{(174)}=-2.59, p<.05, d=.39\right)$.

The findings were generally weaker for agreeableness. As expected, participants high on optimism rated themselves as more agreeable than those low on optimism across rating sessions (zero-acquaintance $t_{(174)}=2.74, p<.01, d=.42$; five-minute interaction $t_{(173)}=2.31, p<.05, d=.35$; nine weeks $t_{(174)}=2.54, p<.05$, $d=.39$ ). However, the optimism of targets had no impact on their group's perceptions of them at any time period (zero-acquaintance $t_{(174)}=-1.23, p=$ n.s; five minute $t_{(174)}=1.05, p=$ n.s.; nine weeks $t_{(174)}=1.05, p=$ n.s.). Optimists may have had a rosier TIPI description of themselves but this was not validated by others who got to know them through their participation in this study.

We performed a $2 \times 3$ (optimism by time) mixed ANOVA on observer ratings of neuroticism where time was treated as a repeated measure. The time by optimism (high-low) interaction was significant $\left(F_{(2,348)}=3.05, p<.05, \eta^{2}=.02\right)$. A single $d f$ contrast analysis revealed that the impact of optimism on group consensus ratings of neuroticism was significantly larger at nine weeks than it was for them mean of the other two time periods $\left(F_{(1,174)}=4.56, p<.05, \eta^{2}=.03\right)$. This suggests that the impact of an optimist's personality on others is negligible on first impressions and only begins to emerge as people become well-acquainted. Furthermore, the impact seems to be limited to only one trait; neuroticism, which is essentially the tendency to experience negative affect (Costa \& McCrae, 1980). 
Established relationships. Q-sort descriptions were provided by two informants whom participants nominated as people who knew them well. The informants were friends, roommates, or family members. Of 182 participants, 156 had the available data to use in these analyses as the Q-Set was added into the procedures after the study had started. If optimism had any significant impact on interpersonal outcomes then we would be sure to find evidence for it within these data. We assessed the impact of optimism by correlating a target's optimism with the average card placement (i.e., the average judgment across two informants of a single personality descriptor statement).

McCrae, Costa, \& Busch (1986) conducted a factor analysis on the California Q-Set and identified the cards that correspond to the five-factor trait model. Table 3 reports the correlations between LOT-R scores and every card in the Q-set that corresponds to neuroticism and agreeableness. Close informants described optimists consistently as being lower in neuroticism (e.g. \#68 "Is basically

Table 3. Q-Set personality descriptions of optimists made by their friends, family, and roommates.

\begin{tabular}{|c|c|c|}
\hline \multicolumn{2}{|c|}{ Q-Set Card } & Optimism \\
\hline \multicolumn{3}{|c|}{ Neuroticism } \\
\hline 84 & Is cheerful. & $.32^{\star * \star a}$ \\
\hline 33 & Is calm, relaxed in manner. & $.22^{* *}$ \\
\hline 10 & Anxiety and tension find outlet in bodily symptoms. & $-.15^{\dagger}$ \\
\hline 23 & Extrapunitive; tends to transfer or project blame. & $-.16^{\dagger}$ \\
\hline 50 & Is unpredictable and changeable in behavior and attitudes. & $-.20^{*}$ \\
\hline 55 & Is self-defeating. & $-.20^{\star}$ \\
\hline 68 & Is basically anxious. & $-.20^{\star}$ \\
\hline 82 & Has fluctuating moods. & $-.23^{* *}$ \\
\hline 72 & $\begin{array}{l}\text { Concerned with own adequacy as a person, either at } \\
\text { conscious or unconscious levels. }\end{array}$ & $-.24^{\star *}$ \\
\hline 34 & Over reactive to minor frustrations; irritable. & $-.31^{\star * *}$ \\
\hline \multirow[t]{2}{*}{22} & Feels a lack of personal meaning in life. & $-.33^{* * *}$ \\
\hline & Agreeableness & \\
\hline 35 & Has warmth; capacity for close relationships. & $.16^{*}$ \\
\hline 28 & Tends to arouse liking and acceptance in people. & .12 \\
\hline 17 & Behaves in a sympathetic or considerate manner. & .10 \\
\hline 14 & Genuinely submissive; accepts domination comfortably. & .03 \\
\hline 5 & Behaves in a giving way toward others. & .02 \\
\hline 37 & Is guileful and deceitful, manipulative, opportunistic. & -.01 \\
\hline 36 & Is subtly negativistic; tends to undermine and obstruct or sabotage. & -.08 \\
\hline 61 & Creates and exploits dependency in people. & -.09 \\
\hline 1 & Is critical, skeptical, not easily impressed. & -.10 \\
\hline
\end{tabular}

Note. The Q-Set task (Block, 1961) was not introduced until the data collection had already begun, so these analyses were performed on $N=156 .{ }^{a} N=155 .{ }^{\dagger} p<.1 .{ }^{*} p<.05 .{ }^{* *} p<.01 .{ }^{* *} p<.001$. 
anxious") and the higher in emotional stability (e.g. \#33 "Is calm, relaxed in manner"). The Q-sort descriptions, however, showed little evidence that people in relationships with optimists view them as being more agreeable, despite the fact that the optimists view themselves that way.

In summary, the easy-going (calm, relaxed, poised) nature of optimists was not noticed by those who interacted with them for the first time. However, after getting to know them for 9 weeks this positive aspect of their personality became known in their relationship. Despite the fact that optimists described themselves as having a more agreeable personality, this was not confirmed by those who knew them.

\section{Discussion}

The primary objective of this report was to respond to the call for more research on the impact of optimism on interpersonal outcomes (Carver et al., 2010; Carver \& Scheier, 2014). We were interested in whether optimists displayed behavioral tendencies that influenced how they were perceived by others. To assess this, we conducted an innovative investigation that lasted over a period of five years with the hope of gleaning an ecologically valid understanding of what separates optimists socially from everyone else. We utilized two sets of informants, unacquainted strangers and well-acquainted friends and family members, to give us an idea of how our optimistic participants were generally perceived. We asked the unacquainted group members to rate the participants at three separate time periods: zero-acquaintance, after a five-minute interaction, and after nine weeks of acquaintance. We asked the friends and family members to complete the Q-Sort procedure with the expectation these well acquainted individuals would provide us with a thorough description of participants' personality.

We found that optimism's relationship to the five-factor constructs varied depending on the personality test used. When the NEO-PI-R was used to assess personality, optimism was associated with lower rates of neuroticism and higher rates of extraversion, agreeableness, and openness. With the exception of conscientiousness, these results closely mapped onto those of previous investigations (Lounsbury et al., 2004; Milligan, 2003; Sharpe et al., 2011). When the very brief TIPI was used to assess personality (within a social context), optimism correlated only with self-descriptions of agreeableness and neuroticism.

In this report, we have suggested that the self-reported TIPI trait descriptions could have been impacted by participants' working self-concept (Markus \& Wurf, 1987), or their public, social selves. Since our optimistic participants perceived themselves as less neurotic and more agreeable, we might have expected these differences to be salient to those who interact with them. Interestingly, we found that whereas optimists viewed themselves as more agreeable, there was little evidence to suggest that anyone else did as well. On the other hand, by nine-weeks of acquaintanceship group members did rate high optimists as being less neurotic than low optimists. Therefore, it is safe to conclude that people do 
generally view optimists as being more emotionally positive (e.g., less sadness, anxiety, hostility, etc.).

The optimistic disposition in this case is characterized by a lower level of negative emotionality that is noticed only by those who are well acquainted with the optimist. This is not to imply that neuroticism and optimism are the same construct, although there is some controversy on this topic. Early critiques of the original Life Orientation Test (Scheier \& Carver, 1985) deemed neuroticism and optimism to be relatively indistinguishable (Smith, Pope, Rhodewalt, \& Poulton, 1989). Soon after, the LOT-R was created (Scheier et al., 1994) to address these concerns, as its relationship to other variables were significant after the effects of neuroticism were controlled for. Nevertheless, we find it intriguing that the only interpersonal consequence we found for optimism was on a trait characterized by the experience of negative affect.

These findings indicate that a self-enhancement bias may be at work for perceptions of agreeableness (Brown, 1986) where optimists evaluated themselves more favorably than others actually perceived them. Also, we found no evidence that within actual social contexts optimists are more extraverted or more conscientious. In fact, when assessing themselves in social contexts the previously published extraversion and conscientious effects vanished (Lounsbury et al., 2004; Milligan, 2003; Sharpe et al., 2011). To the outside world, optimists do not appear to be any more agreeable, extraverted, open, or conscientious than anyone else.

There are of course some limitations to the present investigation. We did not set out to investigate the impact of optimism on interpersonal outcomes when data collection began. If we had we would have included other measures of optimism as well, and would have asked participants to evaluate each other on additional criteria that related to their interpersonal lives. Still, the value of this work is that we now know in what ways, and approximately when, the optimistic personality presents itself and becomes known to others. This was the primary goal of this study, and these findings contribute to the already colossal body of work on the positive influence of optimism by filling a twice lamented gap in the optimism literature (see Carver, et al., 2010; Carver \& Scheier, 2014 for reviews). Positive psychology researchers should have no trouble applying and extending the findings presented here.

In this report we identified what behavioral tendencies optimists actually display to the world around them. We know now that it is not enough to ask optimists how they perceive the world. Because of their nature, researchers will only ever receive a biased and positive response. Instead, we must learn how they influence their social worlds through the eyes of the people they live and work with. Doing so will allow us to extend our understanding of the positive power of optimism to the interpersonal realm.

\section{Acknowledgements}

This research was funded in part by an Undergraduate Research, Innovation, 
Scholarship, and Creativity grant awarded to the first author. Special thanks to Jill Brown, Nicholas Reyna, Hooman Zoonoozy, Alyson Kraus, Ryan Armstrong, Sara Vogan, James Babcock, Jim Scovell, Elysia Todd, Sarah Erickson, Michelle Best, Sarah Noyes, Becky Baker, Jordan Clark, Chris Grooms, Jessica Waldo, Krikor Gazarian, Joshua Landin, Crystal Fisher, Jason Gibbs, Josh Klein, Shaila McCarthy, Naomi Sprague, Stewart Risinger, Jackson Pugh, Matthew Austin, Lisa Furumasu, Laura Romrell, Tiffany Diec, Rebecca Wooldridge, Greg Hagg, Shawna Smith, and Rory Running for their help in conducting this study.

\section{References}

Abend, T. A., \& Williamson, G. M. (2002). Feeling Attractive in the Wake of Breast Cancer: Optimism Matters, and So Do Interpersonal Relationships. Personality and Social Psychology Bulletin, 28, 427-436. https://doi.org/10.1177/0146167202287001

Allik, J., de Vries, R. E., \& Realo, A. (2016). Why Are Moderators of self-Other Agreement Difficult to Establish? Journal of Research in Personality, 63, 72-83. https://doi.org/10.1016/j.jrp.2016.05.013

American Psychological Association (2002). Ethical Principles of Psychologists and Code of Conduct. American Psychologist, 57, 1060-1073. https://doi.org/10.1037/0003-066X.57.12.1060

Biesanz, J. C., West, S. G., \& Millevoi, A. (2007). What Do You Learn about Someone over Time? The Relationship between Length of Acquaintance and Consensus and Self-Other Agreement in Judgments of Personality. Journal of Personality and Social Psychology, 92, 119-135. https://doi.org/10.1037/0022-3514.92.1.119

Block, J. (1961). The Q-Sort Method in Personality Assessment and Psychiatric Research. Springfield, IL: Charles C. Thomas. https://doi.org/10.1037/13141-000

Brissette, I., Scheier, M. F., \& Carver, C. S. (2002). The Role of Optimism in Social Network Development, Coping, and Psychological Adjustment during a Life Transition. Journal of Personality and Social Psychology, 82, 102-111. https://doi.org/10.1037/0022-3514.82.1.102

Brown, J. A., \& Bernieri, F. J. (2017). Trait Perception Accuracy and Acquaintance within Groups: Tracking Accuracy Development. Journal of Personality and Social Psychology, 43, 716-728. https://doi.org/10.1177/0146167217695557

Brown, J. D. (1986). Evaluations of Self and Others: Self-Enhancement Biases in Social Judgments. Social Cognition, 4, 353-376. https://doi.org/10.1521/soco.1986.4.4.353

Carver, C. S., \& Scheier, M. F. (2014). Dispositional Optimism. Trends in Cognitive Sciences, 18, 293-299. https://doi.org/10.1016/j.tics.2014.02.003

Carver, C. S., Scheier, M. F., \& Segerstrom, S. C. (2010). Optimism. Clinical Psychology Review, 30, 879-889. https://doi.org/10.1016/j.cpr.2010.01.006

Chaplin, W. F., Phillips, J. B., Brown, J. D., Clanton, N. R., \& Stein, J. I. (2000). Handshaking, Gender, Personality, and First Impressions. Journal of Personality and Social Psychology, 79, 110-117. https://doi.org/10.1037/0022-3514.79.1.110

Cialdini, R. B. (2008). Turning Persuasion from an Art into a Science. In P. Meusburger (Ed.), Symposium on Knowledge and Space: Clashes of Knowledge (pp. 199-209). Berlin: Springer. https://doi.org/10.1007/978-1-4020-5555-3_12

Costa, P. T., \& McCrae, R. R. (1980). Influence of Extraversion and Neuroticism on Subjective Well-Being: Happy and Unhappy People. Journal of Personality and Social Psychology, 38, 668-678. https://doi.org/10.1037/0022-3514.38.4.668 
Costa, P. T., \& McCrae, R. R. (1992). Neo Personality Inventory-Revised (NEO PI-R). Odessa, FL: Psychological Assessment Resources.

Digman, J. M. (1990). Personality Structure: Emergence of the Five-Factor Model. Annual Review of Psychology, 41, 417-440. https://doi.org/10.1146/annurev.ps.41.020190.002221

Gosling, S. D., Rentfrow, P. J., \& Swann, W. B. (2003). A Very Brief Measure of the Big-Five Personality Domains. Journal of Research in Personality, 37, 504-528. https://doi.org/10.1016/S0092-6566(03)00046-1

Greenwald, A. G. (1980). The Totalitarian Ego: Fabrication and Revision of Personal History. American Psychologist, 35, 603-618. https://doi.org/10.1037/0003-066X.35.7.603

Hall, J. A., Bernieri, F. J., \& Carney, D. R. (2005). Nonverbal Behavior and Interpersonal Sensitivity. In J. A. Harrigan, R. Rosenthal, \& K. R. Scheier (Eds.), The New Handbook of Methods in Nonverbal Behavior Research (pp. 237-282). New York, NY: Oxford University Press.

Heinonen, K., Räikkönen, K., Keltikangas-Järvinen, L., \& Strandberg, T. (2004). Adult Attachment Dimensions and Recollections of Childhood Family Context: Associations with Dispositional Optimism and Pessimism. European Journal of Personality, 18, 193-207. https://doi.org/10.1002/per.508

John, O. P., \& Robins, R. W. (1994). Accuracy and Bias in Self-Perception: Individual Differences in Self-Enhancement and the Role of Narcissism. Journal of Personality and Social Psychology, 66, 206-219. https://doi.org/10.1037/0022-3514.66.1.206

Kenny, D. A. (1994). Interpersonal Perception: A Social Relations Analysis. New York, NY: Guilford Press.

Kenny, D. A., \& West, T. V. (2008). Zero Acquaintance: Definitions, Statistical Model, Findings, and Process. In N. Ambady, \& J. Skowronski (Eds.), First Impressions (pp. 129-146). New York, NY: Guilford Press.

Krueger, J. (1998). Enhancement Bias in Descriptions of Self and Others. Personality and Social Psychology Bulletin, 24, 505-516. https://doi.org/10.1177/0146167298245006

Lounsbury, J. W., Saudargas, R. A., \& Gibson, L. W. (2004). An Investigation of Personality Traits in Relation to Intention to Withdraw from College. Journal of College Student Development, 45, 517-534. https://doi.org/10.1353/csd.2004.0059

Mann, T. (2001). Effects of Future Writing and Optimism on Health Behaviors in HIV-Infected Women. Annals of Behavioral Medicine, 23, 26-33. https://doi.org/10.1207/S15324796ABM2301_5

Markus, H., \& Wurf, E. (1987). The Dynamic Self-Concept: A Social Psychological Perspective. Annual Review in Psychology, 38, 299-237. https://doi.org/10.1146/annurev.ps.38.020187.001503

McCrae, R. R., Costa, P. T., \& Busch, C. M. (1986). Evaluating Comprehensiveness in Personality Systems: The California Q-Set and the Five-Factor Model. Journal of Personality, 54, 430-446. https://doi.org/10.1111/j.1467-6494.1986.tb00403.x

Milligan, M. (2003). Optimism and the Five-Factor Model of Personality, Coping, and Health Behavior. Doctoral Dissertation, Auburn, AL: Auburn University.

Scheier, M. F., \& Carver, C. S. (1985). Optimism, Coping, and Health: Assessment and Implications of Generalized Outcome Expectancies. Health Psychology, 4, 219-247. https://doi.org/10.1037/0278-6133.4.3.219

Scheier, M. F., Carver, C. S., \& Bridges, M. W. (1994). Distinguishing Optimism from Neuroticism (and Trait Anxiety, Self-Mastery, and Self-Esteem): A Reevaluation of the 
Life Orientation Test. Journal of Personality and Social Psychology, 67, 1063-1078. https://doi.org/10.1037/0022-3514.67.6.1063

Sears, S. F., Serber, E. R., Lewis, T. S., Walker, R. L., Conners, N., Lee, J. T., Curtis, A. B., \& Conti, J. B. (2004). Do Positive Health Expectations and Optimism Relate to Quality-of-Life Outcomes for the Patient with an Implantable Cardioverter Defibrillator. Journal of Cardiopulmonary Rehabilitation and Prevention, 24, 324-331. https://doi.org/10.1097/00008483-200409000-00008

Sharpe, J. P., Martin, N. R., \& Roth, K. A. (2011). Optimism and the Big-Five Factors of Personality: Beyond Neuroticism and Extraversion. Personality and Individual Differences, 51, 946-951. https://doi.org/10.1016/j.paid.2011.07.033

Smith, N., Young, A., \& Lee, C. (2004). Optimism, Health-Related Hardiness and Well-Being among Older Australian Women. Journal of Health Psychology, 9, 741-752. https://doi.org/10.1177/1359105304045373

Smith, T. W., Pope, M. K., Rhodewalt, F., \& Poulton, J. L. (1989). Optimism, Neuroticism, Coping, and Symptom Reports: An Alternative Interpretation of the Life Orientation Test. Journal of Personality and Social Psychology, 56, 640-648. https://doi.org/10.1037/0022-3514.56.4.640

Smith, T. W., Ruiz, J. M., Cundiff, J. M., Baron, K. G., \& Nealey-Moore, J. B. (2013). Optimism and Pessimism in Social Context: An Interpersonal Perspective on Resilience and Risk. Journal of Research in Personality, 47, 553-562.

https://doi.org/10.1016/j.jrp.2013.04.006

Srivastava, S., McGonigal, K. M., Richards, J. M., Butler, E. A., \& Gross, J. J. (2006). Optimism in Close Relationships: How Seeing Things in a Positive Light Makes Them So. Journal of Personality and Social Psychology, 91, 143-153. https://doi.org/10.1037/0022-3514.91.1.143

Swann Jr., W. B. (1990). To Be Adored or to Be Known: The Interplay of Self-Enhancement and Self-Verification. In R. M. Sorentino, \& E. T. Higgins (Eds.), Handbook of Motivation and Cognition (Vol. 2, pp. 408-448). New York, NY: Guilford Press.

Wicklund, R. A. (1975). Objective Self-Awareness. Advances in Experimental Social Psychology, 8, 233-275. https://doi.org/10.1016/S0065-2601(08)60252-X

Wiggins, J. S. (1996). The Five Factor Model of Personality: Theoretical Perspectives. New York, NY: Guilford Press.

Wimberly, S. R., Carver, C. S., \& Antoni, M. H. (2008). Effects of Optimism, Interpersonal Relationships, and Distress on Psychosexual Well-Being among Women with Early Stage Breast Cancer. Psychology and Health, 23, 57-72. https://doi.org/10.1080/14768320701204211

Wrosch, C., \& Scheier, M. F. (2003). Personality and Quality of Life: The Importance of Optimism and Goal Adjustment. Quality of Life Research, 12, 59-72.

https://doi.org/10.1023/A:1023529606137 